\title{
Do cannibalistic fish forage optimally? An experimental study of prey size preference, bioenergetics of cannibalism and their ontogenetic variations in the African catfish Heterobranchus longifilis
}

\author{
Etienne BARAS ${ }^{\mathrm{a}}$, Rémi DUGUÉ and Marc LEGENDRE
}

IRD UMR 226, ISE-M, 34095 Montpellier, France

Received 22 July 2014; Accepted 29 September 2014

\begin{abstract}
This study relied on the day-by-day analysis of bioenergetics and prey size preference in isolated cannibals of the African catfish Heterobranchus longifilis (13-57 mm standard length, 3-500 $\mathrm{mg}$ dry body mass, $n=153$ ) that were offered ad libitum conspecific prey of adequate sizes in small-sized (2-L) environments under controlled conditions (12L:12D, $30{ }^{\circ} \mathrm{C}$ ). In these conditions, cannibals of increasing body size selected preferentially prey of decreasing size relative to their own, and increasingly closer to the optimal prey size (producing the highest gross conversion efficiency). The role of experience in cannibalism was found of secondary importance relative to body size, both as regards food intake and prey size selectivity. These results indicate that in environments that minimize the escape capacities of their potential victims, as applies to most aquacultural contexts, fish exercising cannibalism tend to forage optimally, which has rarely been evidenced for piscivorous behaviour. The present study further highlights that $H$. longifilis possesses a very high capacity for growth, which originates from the combination of high food intake and very high conversion efficiency, and makes this species of utmost interest for aquaculturists wherever fast growth is desirable, but also extremely prone to cannibalism wherever feeding schedules are inadequate.
\end{abstract}

Keywords: Cannibalism / Freshwater aquaculture / Fish / Prey size preference / Daily food intake / Gross conversion efficiency / Clariid

\section{Introduction}

The understanding of prey selection, prey size selectivity and their variations with the age or size of predators is central to ecological studies, especially by reference to the "optimal foraging theory", which predicts that an animal eventually tends to select preferentially the prey type or prey size that yields the highest energy return per unit of time in a particular context (Emlen 1966; Pyke et al. 1977; Krebs and Stephens 1986). A similar interest has been raised in aquacultural studies aiming to understand the relative benefits of using a small or large food particle size (for fishes: Wankowski and Thorpe 1979; Goldan et al. 1997; Hasan and Macintosh 2008; Azaza et al. 2010). Small prey are more difficult to detect at long distance (Folkvord 1997), but easier to capture and handle (Knights 1983; Mittelbach and Persson 1998), and unless their gut residence time is excessively brief (Hossain et al. 2000) they can be digested more completely (Persson 1986; Jobling 1987). On the other hand, their absolute energy content is low, so the net energy gain per unit of time can be less than for big

a Corresponding author: etienne.baras@ird.fr prey, depending on food search time and energy invested into foraging (e.g., Jobling and Wandsvik 1983; Dos Santos et al. 1993). These traits account for why the optimal or preferred predator:prey size ratios vary between predatory species with contrasting mouth dimensions (Mittelbach and Persson 1998) and further depend on the predator's size (Werner and Gilliam 1984) or social status (MacLean et al. 2003), as well as on prey morphology (Scharf et al. 1998), behaviour (Wahl and Stein 1988) or density, which altogether govern its probability of encountering predators (for a recent review, see Giacomini et al. 2013).

Studies where the optimal foraging strategy has been validated in fishes generally concerned prey with low or zero mobility (e.g., Werner and Hall 1974; Mittelbach 1981) and not piscine prey or other types of highly mobile prey (e.g., Hoyle and Keast 1987; Hart and Hamrin 1990; reviews in Juanes 1994; Sih and Christensen 2001). However, in environments where escape capacities are limited, the prey size preferences of piscivorous fishes are more likely to follow the optimal foraging theory (at least, if prey of optimal size are available). This working hypothesis, if validated, is of particular interest for predicting the preferred prey sizes of cannibalistic fishes 
under culture conditions and providing practical recommendations for size grading fish to mitigate subsequent cannibalism.

During the early life stages, cannibals most frequently consume incompletely siblings of very large dimensions relative to their own size and there are generally no gape limitations for the exercise of this type of cannibalism, as the victims are swallowed tail first. In larger fish, the victims are swallowed whole and cannibalism is governed by specific morphological restrictions (reviews in Hecht and Pienaar 1993; Folkvord 1997; Baras and Jobling 2002; Baras 2013). Information on the allometric variations of mouth and body dimensions has been used often to predict the occurrence or risk of cannibalism (Hecht and Appelbaum 1988; Brabrand 1995; Hseu et al. 2003, 2004, 2007; Hseu and Huang 2014). In some cases, cannibalistic fishes have been found to ingest siblings near the maximal possible size (e.g., largemouth bass Micropterus salmoides, Johnson and Post 1996; redtail catfish Hemibagrus nemurus, Baras et al. 2013), whereas this "maximalistic" behaviour is infrequent with other types of piscivory (Juanes 1994, 2003; Juanes et al. 2002). However, cannibals generally prefer small over large conspecifics (Atlantic cod Gadus morhua, Folkvord and Otterå 1993; walleye pollock Theragra chalcogramma, Sogard and Olla 1994; Arctic charr Salvelinus alpinus, Amundsen et al. 1995; snakehead Channa striata, Qin and Fast 1996; dorada Brycon moorei, Baras et al. 2000). Evidence has also been provided that cannibals of increasing size tend to select prey that are increasingly smaller relative to their predation capacities (Asian catfish Pangasius djambal, Baras et al. 2010; Amazonian catfish Pseudoplatystoma punctifer, Baras et al. 2011). The bioenergetics of cannibalism has been investigated in several fish species, but the effects of prey size on the growth and food conversion of cannibals have been overlooked. Henceforth, it is uncertain whether ontogenetic variations of prey size preference in cannibalistic fish reflect concomitant variations in optimal prey size.

The present study examined, through a series of predation experiments under controlled conditions, the correspondence between the optimal and preferred prey size in cannibalistic fish of different ages and sizes. In every experiment, prey density was in large excess and cannibals were isolated from each other to avoid any possible effect of competition or dominance hierarchies on the variables under scrutiny (MacLean et al. 2003). The species under study was the vundu catfish Heterobranchus longifilis, a fast growing African clariid catfish of interest for the diversification of freshwater aquaculture (Legendre et al. 1992; Hecht et al. 1996; Otémé et al. 1996), but which requires frequent size grading under culture conditions (Gilles et al. 2001), because of intense cannibalism during its larval and juvenile stages (Baras 1999; Baras et al. 1999; Nwosu and Holzlöhner 2000; Atse et al. 2009).

\section{Methods}

\subsection{Fish and rearing conditions}

The fish used in this study were half siblings of broodfish held captive in the Gamet aquaculture facilities (Groupe aquaculture continentale méditerranéenne et tropicale, Montpellier, France). Hormonal induced breeding, egg fertilisation and incubation were performed according to Legendre (1986). About $48 \mathrm{~h}$ after hatching, fish were transferred to $30-\mathrm{L}$ tanks in an indoor water recirculation system at $28{ }^{\circ} \mathrm{C}$ under 12L:12D and offered freshly hatched nauplii of Artemia sp. One group of fish was selected at random and fed six daily meals in slight excess to produce large individuals to be used as cannibals in the predation experiments. Four other groups of fish were offered three daily meals to provide numerous fish of an adequate size range to be used as prey fish. Faeces, excess food and dead fish were removed with a siphon twice a day (morning, evening). Fish large enough to cannibalise others, to the observer's naked eye, were transferred periodically to separate tanks to minimize cannibalism and make sure that the fish used as future cannibals had no prior experience of cannibalism.

\subsection{Predation experiments}

Predation experiments took place in the same experimental room, but in a separate water recirculation system where no food had been provided to make sure that would be no circulation of free amino acids or other sources of energy. Water temperature was set at $30{ }^{\circ} \mathrm{C}$, which is close to the thermal optimum for growth of larvae and juveniles in this species (Nwosu and Holzlhöner 2000), and dissolved oxygen was near saturation.

The design of predation experiments was as in Baras et al. (2010, 2011, 2013). Briefly in each experiment, a large fish (putative cannibal) was placed for $24 \mathrm{~h}$ together with smaller siblings (prey fish) of known wet body mass $(W M)$ in a predation cage $(2.0 \mathrm{~L}, 15 \times 15 \times 9[\mathrm{~h}] \mathrm{cm})$ that was immersed in a tank of the water recirculation system. No food was offered over $24 \mathrm{~h}$. The size distribution of prey fish was broad enough to enable size selection, but narrow enough to prevent cannibalism between them (on the basis of mouth and body dimensions in H. longifilis; Baras 1999). The number of prey fish ( $n=13-20$, depending on cannibal's size) was in excess of the presumed cannibal's daily needs, except on some occasions, when it was deliberately restricted $(n=0-5)$ to document the relationships between growth and food intake for a broad range of feeding levels. The latter situations were not retained for the study of prey size preference. Every $24 \mathrm{~h}$, the cannibal was gently captured, weighed (nearest $0.1 \mathrm{mg}$ ) under anaesthesia (2-phenoxy-ethanol, $0.4 \mathrm{ml} \mathrm{L}^{-1}$ ) and returned to its enclosure, together with a new group of prey fish. Surviving prey fish were measured and their distribution was compared with the initial size distribution to determine which individuals had been eaten (detailed protocol in Baras et al. 2010, 2011). No surviving prey fish was reused in any subsequent predation experiment to avoid biases originating from protracted or repeated food deprivation and experience in evading cannibals' attacks.

Every day of experiment, two control groups containing exclusively prey fish, with a similar size distribution as in the predation cages, were prepared. One group was euthanized with an excess dose of anaesthetics (2-phenoxy-ethanol, $\left.2.0 \mathrm{ml} \mathrm{L}^{-1}\right)$, placed at $105^{\circ} \mathrm{C}$ overnight then weighed again for the measure of dry body mass (DM; AOAC 1995). The other control group was examined after $24 \mathrm{~h}$ of food deprivation to 
Table 1. Characteristics of the experiments for studying the bioenergetics and prey size preference in larvae and juveniles of African catfish $H$. longifilis. WM is the fish wet body mass, $D M$ is its dry body mass and $S L$ is its standard body length of the cannibal (ci) or prey $(i)$ at the start of each period of $24 \mathrm{~h}$ of observation. Contingency table analyses test for random prey selection in each size category (1-8); using exclusively the situations where prey fish were in excess. Situations where fish were food restricted (values between parentheses) were used for the study of bioenergetics only.

\begin{tabular}{|c|c|c|c|c|c|c|c|c|}
\hline & \multicolumn{8}{|c|}{ Cannibal size categories } \\
\hline & 1 & 2 & 3 & 4 & 5 & 6 & 7 & 8 \\
\hline Cannibal $W M_{c i}(\mathrm{mg})$ & 41.1 & 93.7 & 148.8 & 228.7 & 336.3 & 454 & 853 & 1766 \\
\hline mean range & $22.7-62.6$ & $63.3-118.9$ & $120.0-172.2$ & $176.2-278.5$ & $291.3-376.5$ & $384-525$ & $547-1209$ & $1218-2381$ \\
\hline Cannibal $D M_{c i}(\mathrm{mg})$ & 6.3 & 15.4 & 25.3 & 40.4 & 61.2 & 85 & 168 & 370 \\
\hline mean range & $3.2-9.9$ & $10.0-19.9$ & $20.0-29.7$ & $30.4-49.9$ & $52.4-69.2$ & 70-99 & $104-245$ & $251-511$ \\
\hline Cannibal $S L_{c i}(\mathrm{~mm})$ & 15.3 & 20.0 & 23.3 & 26.7 & 30.2 & 33.3 & 40.5 & 51.2 \\
\hline mean range & $12.8-17.6$ & $17.7-21.6$ & $21.7-24.4$ & $24.6-28.5$ & $28.9-31.3$ & $31.4-35.0$ & $35.4-45.6$ & $45.7-56.6$ \\
\hline $\begin{array}{l}n \text { observations }(\text { day } \times \text { fish) } \\
\text { ad libitum (food-restricted) }\end{array}$ & $20(15)$ & $15(4)$ & $9(6)$ & $12(9)$ & $18(3)$ & $17(2)$ & $37(13)$ & $25(6)$ \\
\hline$n$ prey offered & 392 & 298 & 180 & 181 & 270 & 255 & 488 & 315 \\
\hline$n$ prey eaten & 95 & 68 & 47 & 57 & 61 & 80 & 168 & 104 \\
\hline Prey $D M_{i}(\mathrm{mg})$ range & $0.3-1.9$ & $0.8-3.9$ & $1.5-4.8$ & $1.6-8.4$ & $2.5-10.4$ & $2.8-11.0$ & $3.9-23.6$ & $8.7-26.0$ \\
\hline Prey size selectivity $\chi^{2}(d f)$ & $42.1(17)$ & $26.1(15)$ & $25.6(11)$ & $28.1(9)$ & $17.5(8)$ & $13.1(6)$ & $14.4(7)$ & $13.8(5)$ \\
\hline$\left(1 \% D M_{c i}\right.$ classes $) p$ & *** & $*$ & $* *$ & $* * *$ & $*$ & $*$ & $*$ & $*$ \\
\hline
\end{tabular}

$*$, ** and *** stand for $p<0.05, p<0.01$ and $p<0.001$, respectively.

test whether complete cannibalism had occurred between prey fish, and measure weight loss during starvation, which was indispensable for identifying the victims of cannibals and estimating their daily food intake. The $D M: W M$ ratio after $24 \mathrm{~h}$ starvation was also measured in this group, using the same protocol as above.

In total, four series of experiments (A-D) were conducted, each with seven individual cannibals, which were studied over six to eight consecutive days, producing a total of 217 day $\times$ fish. The cannibals under study ranged from 12.8 to $56.6 \mathrm{~mm}$ in standard length $S L$, (corresponding $W M$ of $23-2381 \mathrm{mg}$ and $D M$ of 3.2 to $511 \mathrm{mg}$ ). No investigation was done in fish $<12 \mathrm{~mm} S L$ (20 mg WM), as cannibalism in such small fish generally consists in an incomplete ingestion of the prey (Baras 1999), which makes it impossible to determine accurately the food intake of cannibals.

\subsection{Calculations}

Variables and calculations were as in Baras et al. (2010, 2011, 2013). All calculations were made on the basis of $D M$ preferentially to $W M$, as the energy contents of small fish vary substantially with increasing fish size, essentially because of decreasing hydration (Kamler 1992), and estimations of growth or energy transformation on the basis of wet body mass frequently produce biases (Canale and Breck 2013). Analyses were done on a daily basis, because $H$. longifilis grows very rapidly, and the capacity for growth and conversion efficiency vary considerably with increasing body size, especially in small fish.

The daily growth rate of cannibals $\left(G, \% D M_{c i}\right.$ day $\left.^{-1}\right)$ was calculated as:

$$
G=100\left(D M_{c f}-D M_{c i}\right) \times D M_{c i}^{-1}
$$

where $D M_{c f}$ and $D M_{c i}$ are the dry masses of cannibals at 24-h intervals.

The gross conversion efficiency ( $G C E, D M: D M)$ was calculated as $G C E=G \times F I^{-1}$, where $G$ is the daily growth rate of cannibals and $F I$ is their daily food intake (both in $\% D M_{c i}$ day $\left.^{-1}\right)$. The value of $F I$ was calculated as $F I=$ $\left[\sum 0.01\left(1-0.5 W C_{f}-0.5 W C_{i}\right)\left(0.5 W M_{f}+0.5 W M_{i}\right)\right] D M_{c i}^{-1}$, where $W C$ is the water content $(\%)$ of eaten prey fish, $W M$ is their wet body mass (mg), and suffixes $f$ and $i$ stand for final and initial, respectively. The value of $W M_{f}$ was calculated as $W M_{f}=W M_{i}(1-W M L)$, where $W M L$ is the proportion of $W M$ lost during $24 \mathrm{~h}$ of food deprivation (data from the second control group).

The analysis of prey size preference relied on the comparison between eaten and available prey. Prey size was expressed as a proportion of the cannibal's dry mass $D M_{c i}$ and categorised into $1 \%$ intervals. Data were pooled in eight size categories of cannibals (Table 1), as a compromise between accuracy (size range) and statistical relevance (number of observations). In each size category of cannibals, the preference index $\left(I_{p}\right)$ of a particular prey size class was calculated as $I_{p}=n_{e} \times n_{a}^{-1}$, where $n_{e}$ and $n_{a}$ are the numbers of eaten and available prey in this size class. Classes with $n_{a}<5$ were not taken into account for the calculation of $I_{p}$. In order to enable direct comparisons between cannibals of different sizes, $I_{p}$ values were normalized (i.e., the highest value was set at 1.00).

\subsection{Data analysis and statistics}

The estimation of the optimal (most energetically profitable) prey size $\left(D M_{o p t}\right)$ and its variation in cannibals of different sizes $\left(D M_{c i}\right)$ was achieved in four steps.

- A stepwise multiple-regression analysis was used to test for the influence of cannibal's size $\left(D M_{c i}, \mathrm{mg}\right)$, food intake 
$\left(F I, \% D M_{c i}\right)$ and mean size of eaten prey $\left(D M_{i}, \% D M_{c i}\right)$ on the daily growth $G\left(\% D M_{c i}\right.$ day $\left.^{-1}\right)$ of individual cannibals. Variables were tested in linear, quadratic and logarithmic format, alone and in interaction (e.g., $F I \times \log D M_{c i} \times$ $\left.\log D M_{c i}\right)$.

- The relationship between $F I$ and $G$ was examined (regression analyses) in the eight size categories of cannibals to determine whether GCE increased continuously with increasing $F I$ or attained a plateau at submaximal values of $F I$, and whether these trends were consistent among size categories; these analyses also gave the opportunity of documenting size-dependent variations of the negative growth during starvation $\left(G_{s}, \% D M_{c i}\right)$ and maintenance food ration $\left(R_{\text {maint }}, \% D M_{c i}\right.$, i.e., the food intake that produces zero growth) in cannibalistic $H$. longifilis.

- The values of FI producing the highest GCE values were identified, and substituted in the stepwise regression model, along with those $D M_{c i}$, so as to identify the optimal prey $\left(D M_{o p t}\right)$ for a particular cannibal of dry mass $D M_{c i}$.

- Finally, $D M_{o p t}$ was equated to $D M_{c i}$.

As regards prey size preference, contingency tables analyses were used to test for random prey size selection in each size category of cannibals, and whether cannibals of different sizes exhibited different preferences. The relationship between the preferred prey size $D M_{\text {pref }}$ and $D M_{c i}$ was described with a regression analysis, using the mean $D M_{c i}$ of cannibals in each size category. Finally, the modelled values of $D M_{o p t}$ and $D M_{\text {pref }}$ were compared for cannibals of different sizes.

Three additional analyses were performed to test whether the $D M_{\text {pref }}: D M_{\text {opt }}$ ratio:

- varied with individual experience in cannibalism, as measured by the number of days in the predation cages (regression analysis);

- was dependent on the number of prey eaten daily by the cannibal (unpaired $t$-tests for $n$ prey $<$ and $\geq 4$ );

- varied between individual fish (one-way ANOVA on ratios corrected for the influence of the two variables evaluated in the two preceding steps).

These three analyses were performed separately in each of the four series of predation experiments. In all instances, null hypotheses were rejected at $p<0.05$.

\section{Results}

No cannibal died during the study and none of them starved over $24 \mathrm{~h}$ when prey fish were available. No ingestion of whole fish occurred in the control groups, but truncated, partially consumed fish were found on three occasions, thereby indicating that incomplete cannibalism could occur between prey fish. Truncated prey were observed in the predation cages on six occasions (cannibals $<20 \mathrm{mg} D M$ ). None of these situations was retained for any analysis (bioenergetics or prey size preference), as it was uncertain whether the victims had been eaten by the cannibal or other prey fish. Fifty-eight other situations, where the number of prey fish had been restricted deliberately, were not retained for the analysis of prey size preference. In the 153 remaining situations (Table 1), cannibals

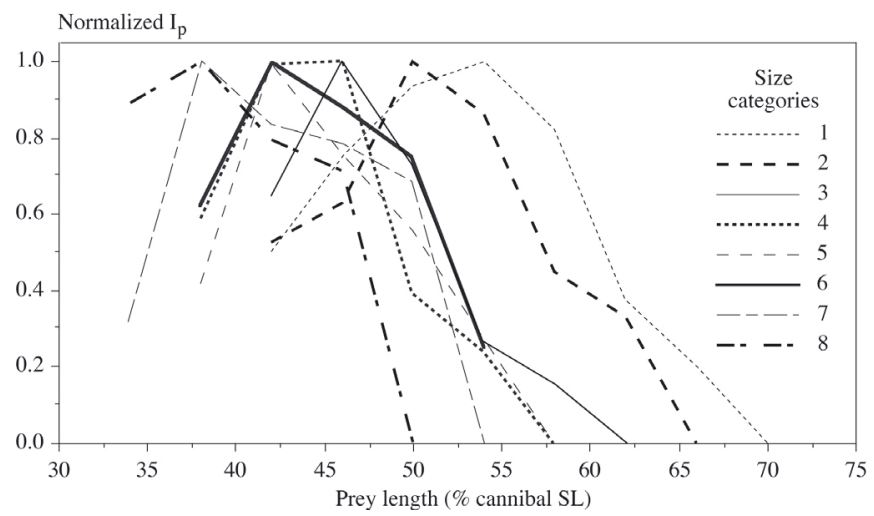

Fig. 1. Prey size preference in cannibalistic catfish, H. longifilis of different sizes (categories 1-8 as in Table 1). For each category, the preference index $\left(I_{p}\right)$ is normalized so that the maximum is 1.00. Prey size is expressed as a proportion of the cannibal's dry body mass $\left(D M_{c i}\right)$. The relationship between $D M_{c i}$ and preferred prey size $\left(D M_{\text {pref }}\right.$, \% $\left.D M_{c i}\right)$, stands as: $\log D M_{\text {pref }}=1.163-0.205\left(\log D M_{c i}\right)\left(r^{2}=0.960\right.$, $F=143.1, d f=7, p<0.0001$ for both coefficients).

consumed 680 of 2379 prey (28.6\%) and no single cannibal was short of prey at the end of any experimental day.

Over the size range under study (1-500 mg DM, 8-57 mm $S L$ ), the relationships between the $D M, W M$ and $S L$ of $H$. longifilis were best described by third order polynomials, i.e.:

$$
\begin{aligned}
\log W M= & -3.771+6.215(\log S L) \\
& -1.823(\log S L)^{2}+0.338(\log S L)^{3}, \\
& \left(r^{2}=0.997, d f=182, F=64602, p<0.0001\right),
\end{aligned}
$$

and

$$
\begin{aligned}
D M(\% W M)= & 7.879+6.175(\log W M) \\
& -1.388(\log W M)^{2}+0.222(\log W M)^{3}, \\
& \left(r^{2}=0.990, d f=49, F=4,569, p<0.0001\right) .
\end{aligned}
$$

\subsection{Prey size preference}

The hypothesis of random prey selection was rejected in all size categories of cannibals (Table 1). All pairwise differences between size categories were significant (contingency table analysis, $p<0.05$ ), except between categories 3 and 4 (cannibals of 20-30 and 30-50 mg $D M_{c i}$ ). Cannibals of increasing sizes preferred prey that were increasingly smaller relative to their own size: the value of $D M_{\text {pref }}$ passed from 9 $10 \%$ in cannibals $<10 \mathrm{mg} \mathrm{DM}$ to $4-5 \%$ in cannibals $>250 \mathrm{mg}$ $D M_{c i}$ (Fig. 1). In all size categories, the size of the largest prey ingested by cannibals was about twice as large as $D M_{\text {pref }}$. The relationship between $D M_{\text {pref }}\left(\% D M_{c i}\right)$ and $D M_{c i}(\mathrm{mg})$ was best modelled with a simple power regression analysis (equation in caption of Fig. 1). The model predicted a relative decrease of $D M_{\text {pref }}$ of about $20 \%$ for each 10-fold increase of $D M_{c i}$. 
Table 2. Energetics of cannibalism in H. longifilis. The eight equations in the upper part of the table refer to the models between growth $(G$, $\% D M_{c i}$ day $^{-1}$ ) and daily food intake $\left(F I, \% D M_{c i}\right)$ illustrated in Figure 2 (size categories as in Table 1). $D M_{c i}$ is the dry body mass (mg) of the cannibal at the start of a 24-h period over which $F I$ and $G$ are measured. The lower part of the table gives the equations that model the ontogenetic variations (against $\left.D M_{c i}\right)$ of maximum daily food intake $\left(F I_{\max }\right)$, maximum growth $\left(G_{\max }\right)$, maximum gross conversion efficiency $\left(G C E_{\max }, D M: D M\right)$, maintenance food ration $\left(R_{\text {maint }}, \% D M_{c i}\right)$ and negative growth during $24 \mathrm{~h}$ of food deprivation $\left(G_{S}, \% D M_{c i}\right.$ day $\left.{ }^{-1}\right)$. The models for $F I_{\max }, G_{\max }$ and $G C E_{\max }$ are deduced from the highest scores observed in cannibals of different sizes (Fig. 3). The models for $R_{\text {maint }}$ and $G_{s}$ are obtained from the eight models given in the upper part of the table.

\begin{tabular}{|c|c|c|c|c|c|}
\hline Bioenergetic model calculations & \multirow[t]{2}{*}{$r^{2}$} & \multirow[t]{2}{*}{$F$} & \multirow[t]{2}{*}{$d f$} & $\begin{array}{c}p \\
\text { intercept } \\
\end{array}$ & $\begin{array}{c}p \\
\text { slope }\end{array}$ \\
\hline \multicolumn{3}{|l|}{ Size category } & & & \\
\hline $1: G=-5.928+0.664 F I$ & 0.986 & 2372.4 & 34 & $* * * *$ & $* * * *$ \\
\hline $2: G=-4.394+0.692 F I$ & 0.981 & 894.3 & 18 & $* * *$ & $* * * *$ \\
\hline 3: $G=-3.949+0.777 F I$ & 0.990 & 1859.4 & 14 & $* * * *$ & $* * * *$ \\
\hline $4: G=-3.508+0.808 F I$ & 0.985 & 810.1 & 20 & $* *$ & $* * * *$ \\
\hline $5: G=-3.210+0.807 F I$ & 0.978 & 831.3 & 20 & $* * * *$ & $* * * *$ \\
\hline $6: G=-2.786+0.802 F I$ & 0.988 & 1375.3 & 18 & $* * *$ & $* * * *$ \\
\hline $7: G=-2.486+0.787 F I$ & 0.991 & 5483.9 & 49 & $* * * *$ & $* * * *$ \\
\hline $8: G=-1.909+0.784 F I$ & 0.989 & 2637.5 & 30 & $* * * *$ & $* * * *$ \\
\hline $\log F I_{\max }=2.133-0.212 \log D M_{c i}$ & 0.961 & 393.9 & 17 & $* * * *$ & $* * * *$ \\
\hline $\log G_{\max }=1.900-0.165 \log D M_{c i}$ & 0.915 & 171.7 & 17 & $* * * *$ & $* * * *$ \\
\hline $\log G C E_{\max }=0.442+0.328\left(\log D M_{c i}\right)-0.077\left(\log D M_{c i}\right)^{2}$ & 0.979 & 347.2 & 17 & $* * * *$ & $* * * *$ \\
\hline $\log R_{\text {maint }}=1.165-0.311 \log D M_{c i}$ & 0.981 & 309.0 & 7 & $* * * *$ & $* * * *$ \\
\hline $\log \left(-G_{s}\right)=0.976-0.268 \log D M_{c i}$ & 0.994 & 1046.1 & 7 & $* * * *$ & $* * *$ \\
\hline
\end{tabular}

$* *, * * *$ and $* * * *$ stand for $p<0.01, p<0.001$ and $p<0.0001$, respectively.

\subsection{Bioenergetics}

In all eight size categories of cannibals, the relationship between $F I$ and $G$ was systematically best described by a simple linear regression analysis with a negative intercept (Table 2, Fig. 2), thereby indicating that GCE increased continuously with increasing FI. Not every individual cannibal fed maximally on every day during the present study (Fig. 2). The relationship between $F I_{\max }$ and $D M_{c i}$ was constructed exclusively from the highest values of $F I$ in fish of different sizes (18 data points, from 16 different individual fish) and was best described with a simple power regression model (Table 2; Fig. 3a). The model indicated that $F I_{\max }$ was as high as $108 \% D M_{c i}$ in a $3-\mathrm{mg}\left(D M_{c i}\right)$ cannibal and decreased by a $39 \%$ margin for each 10 -fold increase of $D M_{c i}$. A similar analysis on the highest growth performances $\left(G_{\max }\right)$ provided evidence that $G_{\max }$ also decreased in cannibals of increasing size, but less rapidly than did $F I_{\max }(-32 \%$ vs. $-39 \%$ for each 10-fold increase of $D M_{c i}$, Table 2, Fig. 3b). The difference between the size-dependent variations of $F I_{\max }$ and $G_{\max }$ reflected both the decrease of weight loss during starvation $\left(G_{s}\right.$; Table 2) and the increase of $G C E$ in cannibals of increasing size (from 0.60 at $3 \mathrm{mg} D M_{c i}$ to $0.75-0.80$ in fish $>30 \mathrm{mg}$ $D M_{c i}$, Fig. 3c).

The observations herein came from four series of experiments in which cannibals were initially naive and possibly gained experience in exercising cannibalism. Henceforth, it was tested whether the $F I$ of individual cannibals varied with increasing time in the predation cages and associated experience in exercising cannibalism. The value of $F I_{\max }$ decreased significantly with increasing $D M_{c i}$ (Fig. 3a); hence, the observed food intakes $\left(F i_{o b s}\right)$ were expressed as a proportion (\%) of $F I_{\text {max }}$ to remove size effects. In every series, $F I_{o b s}$ was highest on the first feeding day and decreased slightly (by $2.2-2.8 \%$
$F I_{\max }$ day $^{-1}$ ) thereafter, but none of these variations was significant (simple linear regression analyses: $p$ of $0.203,0.163$, 0.140 and 0.111 in series A, B, C and D, respectively). Similar tests on $G_{o b s}$ (vs. $\left.G_{\max }\right)$ and $G C E_{o b s}\left(v s . G C E_{\max }\right)$ gave similar results $(p>0.05$ in every situation), thereby suggesting that the degree of experience in cannibalism did not affect significantly $F I, G$ or $G C E$ in the present study.

\subsection{Optimal prey size}

In absence of significant effects of individual experience on the bioenergetics of cannibalism, a general growth model could be constructed from the 153 situations (i.e., day $\times$ cannibal; Table 3 ). The stepwise multiple-regression analysis produced a four-variable model $\left(R^{2}=0.979\right)$, with each variable consisting in an interaction (i.e., a mathematical product) between food intake $(F I)$, cannibal size $\left(\log D M_{c i}\right)$ or prey size $\left(\log D M_{i}\right)$, in simple or quadratic forms. As illustrated in Figure 4, the model indicated that (i) at any $D M_{c i}$, the relationship between $G C E$ and prey size $\left(D M_{i}\right)$ in cannibals eating identical amounts of food was shaped as an asymmetric dome; (ii) in cannibals feeding maximally, the value of $G C E$ increased in a curvilinear way with increasing $D M_{c i}$; and (iii) the optimal prey size $\left(D M_{o p t}\right)$ was independent of $F I$ and decreased in a curvilinear way with increasing $D M_{c i}$, from $>7.5 \% D M$ in cannibals smaller than $10 \mathrm{mg} D M_{c i}$ to $<5 \%$ in cannibals larger than $200 \mathrm{mg} D M_{c i}$ (Fig. 4).

The comparison between the preferred $\left(D M_{\text {pref }}\right)$ and optimal prey sizes $\left(D M_{o p t}\right)$ revealed that small cannibals preferred eating prey larger than $D M_{\text {opt }}$ (Fig. 5). The difference between the two variables decreased in cannibals of increasing size and became tenuous in fish larger than $60 \mathrm{mg} D M_{c i}$. In the two series of experiments (A and B) with the smallest cannibals $\left(D M_{c i}\right.$ of 3-80 mg); the $D M_{\text {pref }}$ : $D M_{\text {opt }}$ ratio decreased 

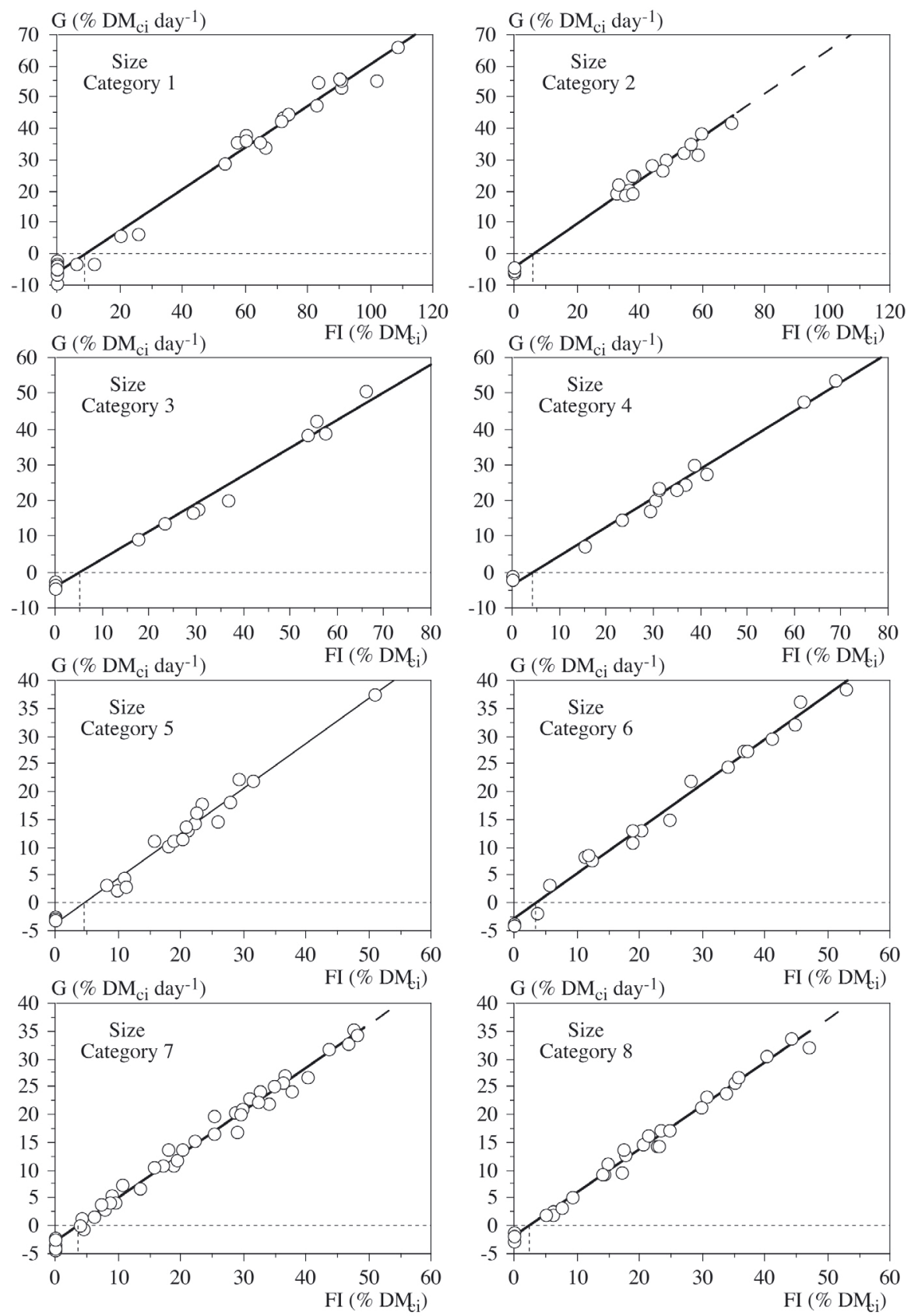

Fig. 2. Relationships between growth $(G)$ and daily food intake $(F I)$ in cannibalistic H. longifilis of different sizes (1-8, as in Table 1). DM $i$ is the dry body mass $(\mathrm{mg})$ of cannibals at the start of the 24-h period over which growth and food intake are measured. Data points refer to individual measurements. In each graph, the vertical dotted line indicates the food ration that produces zero growth $\left(R_{\text {maint }}\right)$. The equations and statistics of the simple regression models are given in Table 3.

Table 3. General growth $\left(G, \% D M_{c i}\right.$ day $\left.^{-1}\right)$ model of cannibalistic larvae and juvenile cannibals of $H$. longifilis, as a function of cannibal's dry body mass $\left(D M_{c i}, \mathrm{mg}\right)$, prey dry mass $\left(D M_{i}, \% D M_{c i}\right)$ and food intake $\left(F I, \% D M_{c i}\right)$. Model constructed by stepwise multiple-regression analysis $\left(R^{2}=0.979, F=1702, d f=152\right)$.

\begin{tabular}{cccc}
\hline Variable & Coeff. [Std. error] & $F$-value & $p$-value \\
\hline Intercept & $-3.652[0.394]$ & 85.9 & $* * * *$ \\
$F I\left(\log D M_{i}\right)$ & $1.281[0.104]$ & 151.3 & $* * * *$ \\
$F I\left(\log D M_{i}\right)^{2}$ & $-0.723[0.084]$ & 73.9 & $* * * *$ \\
$F I\left(\log D M_{c i}\right)$ & $0.173[0.030]$ & 33.5 & $* * * *$ \\
$F I\left(\log D M_{c i}\right)^{2} \times\left(\log D M_{i}\right)^{2}$ & $-0.036[0.014]$ & 6.51 & $*$ \\
\hline
\end{tabular}

$*$ and $* * * *$ stand for $p<0.05$ and $p<0.0001$, respectively. 

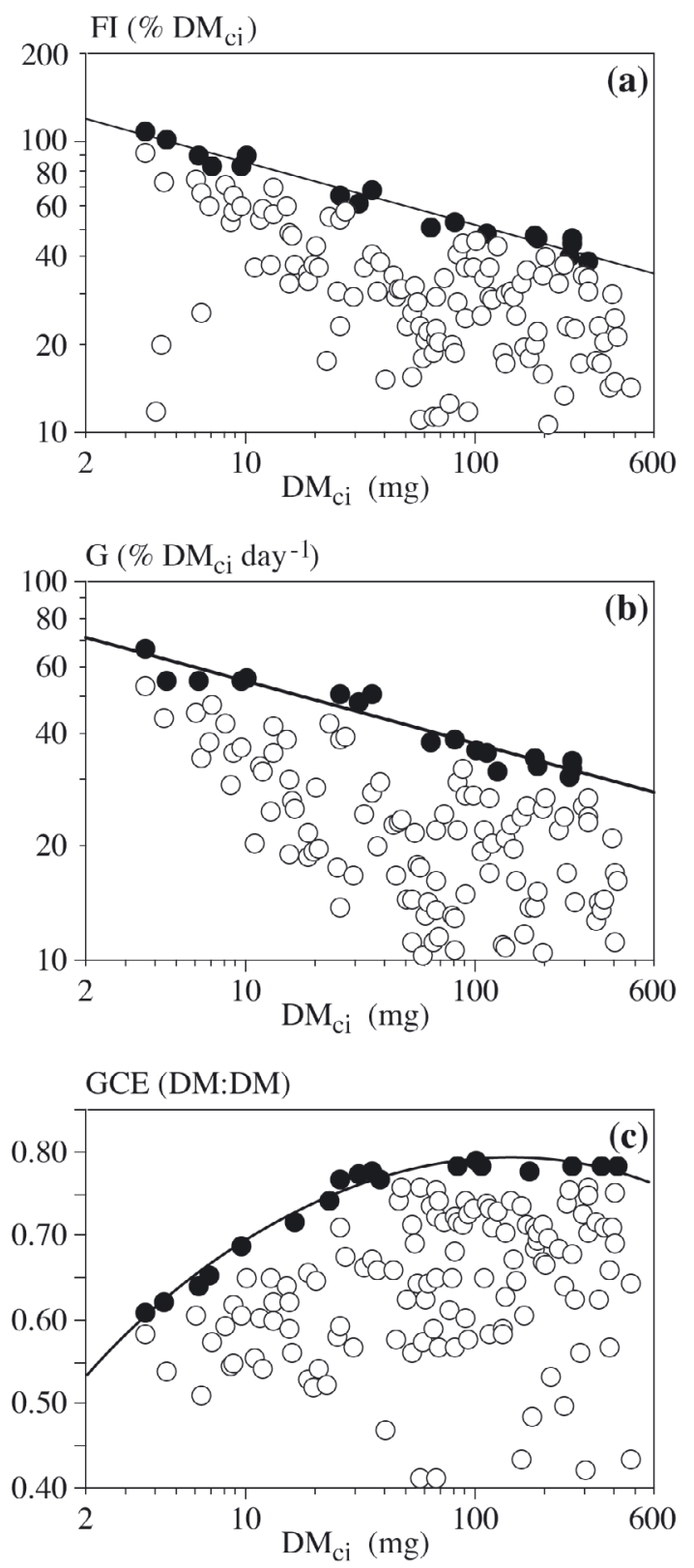

Fig. 3. Size-dependent variation of daily food intake $(F I)$, growth $(G)$ and gross conversion efficiency (GCE, DM:DM) in cannibalistic $H$. longifilis. $D M_{c i}$ is the dry body mass $(\mathrm{mg})$ of cannibals at the start of the 24-h period over which growth and food intake are measured. Data points refer to individual measurements. Models are constructed from the highest points only (dark circles; equations and statistics in Table 3).

significantly with increasing time in the predation cages (Table 4). No such decline was observed in larger fish (series C and $\mathrm{D}, D M_{c i}>80 \mathrm{mg}$ ), which preferred prey sizes close to $D M_{\text {opt }}$ throughout the experiments. The $D M_{\text {pref }}$ : $D M_{\text {opt }}$ ratio was not affected by the number of eaten prey (Table 4), except in the largest cannibals $\left(D M_{c i}>200 \mathrm{mg}\right)$, which preferred prey sizes close to $D M_{\text {opt }}$ when eating many prey, but selected larger prey when eating a few of them. Analyses of variance on $D M_{\text {pref }}$ : $D M_{\text {opt }}$ ratios (corrected for the two aforementioned

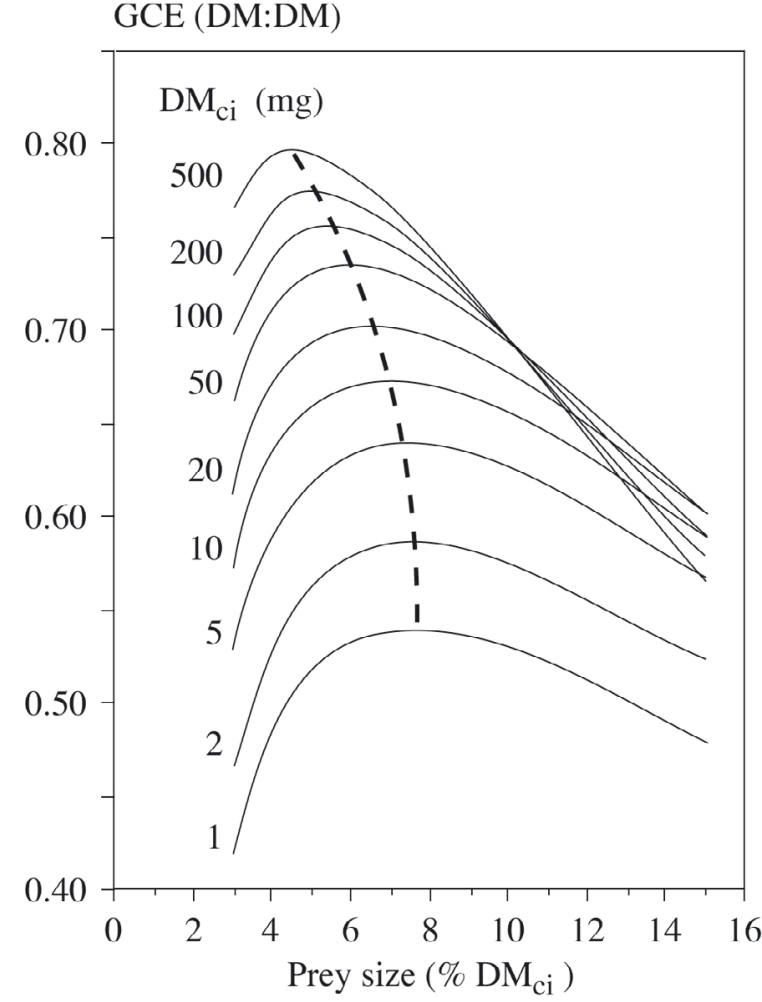

Fig. 4. Variations of gross conversion efficiency $(G C E)$ in cannibalistic $H$. longifilis feeding maximally, as a function of the dry body mass of cannibals $\left(D M_{c i}, \mathrm{mg}\right)$ and prey size $\left(\% D M_{c i}\right)$. The dotted curve shows the variation of the optimal prey size $\left(D M_{o p t}, \% D M_{c i}\right)$ in cannibals of different $D M_{c i}$. Its equation stands as: $\log D M_{o p t}=0.8844$ $0.0162\left(\log D M_{c i}\right)-0.0271\left(\log D M_{c i}\right)^{2}\left(\mathrm{r}^{2}>0.999\right.$, no statistics given, as deduced from modeled values).

effects) did not indicate any significant individual fish effect (Table 4).

\section{Discussion}

In synthesis, the present study provided evidence that (i) isolated cannibals of Heterobranchus longifilis exhibit marked prey size selectivity and eat preferentially prey of decreasing size relative to their own during the larval and early juvenile stages; (ii) the relationship between growth and prey size is dome-shaped, and the optimal prey size $\left(D M_{\text {opt }}\right)$ decreases in cannibals of increasing size; (iii) young naive cannibals of $H$. longifilis prefer eating prey that are larger than $D M_{o p t}$; (iv) as cannibals increase in size, they select prey increasingly closer to $D M_{\text {opt }} ;(\mathrm{v})$ this variation does not exclusively reflect the cannibal's experience, as large fish without any prior experience of cannibalism readily prefer prey sizes close to $D M_{\text {opt }}$, except when they eat very few prey and select much larger fish.

\subsection{Bioenergetics}

The maximal food intakes of isolated cannibals in the present study were high and similar to those reported for cannibals of $H$. longifilis reared communally (Baras et al. 1999) and 
Table 4. Effect of "experience" (number of days in the predation cages), number of eaten prey and individual identity on the ratio between the preferred and optimal prey size $\left(D M_{\text {pref }}\right.$ : $\left.D M_{\text {opt }}\right)$ in $H$. longifilis. Four series of experiments A-D, each with seven individual fish of dry body mass $D M_{c i}$, with no prior experience in cannibalism. (a) simple linear regression analyses; (b) unpaired $t$-tests on $D M$ ratios corrected for the effect of experience; (c) one-way analysis of variance on $D M$ ratios corrected for the effects of the other two factors.

\begin{tabular}{ccccccc}
\hline $\begin{array}{c}\text { Exp. } \\
\text { series }\end{array}$ & $\begin{array}{c}D M_{c i} \\
(\mathrm{mg})\end{array}$ & $\begin{array}{c}n \text { data } \\
(\text { days })\end{array}$ & $\begin{array}{c}D M_{\text {pref }}: D M_{\text {opt }} \text { ratio } \\
(\text { mean } \pm \mathrm{SD})\end{array}$ & $\begin{array}{c}\text { "Experience" } \\
\text { (a) }\end{array}$ & $\begin{array}{c}n \text { eaten } \\
\text { prey }(\mathrm{b})\end{array}$ & $\begin{array}{c}\text { Individual } \\
\text { fish }(\mathrm{c})\end{array}$ \\
\hline $\mathrm{A}$ & $<25$ & $40(7)$ & $1.59 \pm 0.31$ & $\begin{array}{c}r=-0.326 \\
p=0.0399\end{array}$ & $p=0.3337$ & $p=0.5439$ \\
& & & $1.15 \pm 0.25$ & $\begin{array}{c}r=-0.487 \\
p=0.0005\end{array}$ & $p=0.2633$ & $p=0.4321$ \\
$\mathrm{~B}$ & $25-79$ & $47(7)$ & $1.00 \pm 0.14$ & $\begin{array}{c}r=0.295 \\
p=0.0898\end{array}$ & $p=0.2099$ & $p=0.1933$ \\
$\mathrm{C}$ & $80-200$ & $34(5)$ & $1.09 \pm 0.23$ & $\begin{array}{c}r=-0.032 \\
p=0.9061\end{array}$ & $p=0.0192$ & $p=0.8903$ \\
$\mathrm{D}$ & $>200$ & $32(5)$ & & & & \\
\hline
\end{tabular}

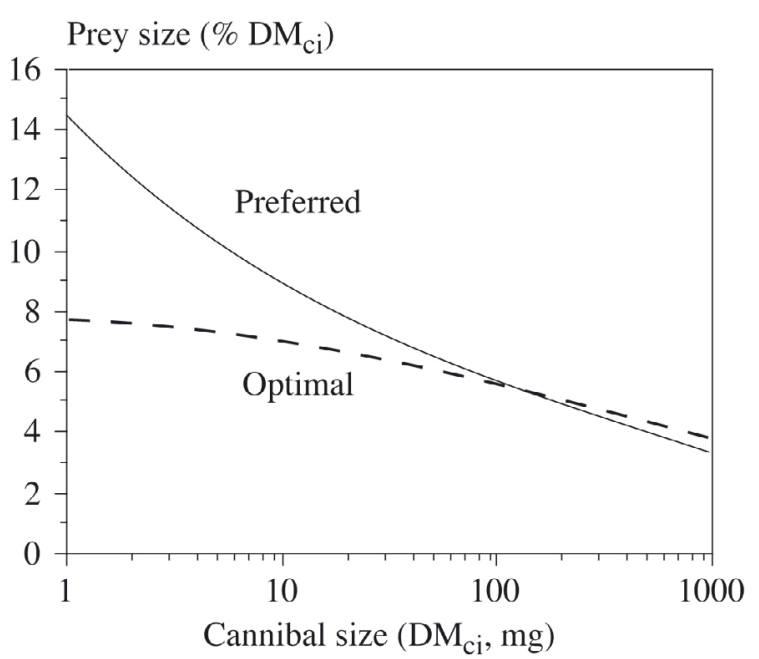

Fig. 5. Size-dependent variations of preferred prey size (plain curve) and optimal prey size (thick dotted curve) in cannibalistic H. longifilis. Equations of the models for preferred and optimal prey sizes in captions of Figures 1 and 4, respectively.

for juveniles of $H$. longifilis fed formulated feed (Kerdchuen and Legendre 1994; after conversion in terms of energy intake, see the calculation in Baras et al. 1999). However, the growth rates and associated $G C E$ values documented here were about twice as high as in the aforementioned studies. The major difference was that here cannibals were studied in isolation $v s$. in small groups in previous studies, thereby suggesting that interactions between young cannibals of $H$. longifilis (competition or dominance hierarchies) could have a determining impact on their $G C E$ and growth. Furthermore, the water temperature here was higher than in the other studies $\left(30\right.$ vs. $\left.28{ }^{\circ} \mathrm{C}\right)$ and closer to the thermal optimum for growth $\left(T_{o p t}^{\circ}\right.$; Nwosu and Holzlöhner 2000). This can account for some difference between growth rates, but probably not as regards GCE, which is generally maximal a few degrees below $T_{o p t}^{\circ}$ (synthesis in Jobling 1994).

As in other studies upon the bioenergetics of cannibalism in fishes (Baras et al. 2010, 2011, 2013), the GCE of cannibalistic $H$. longifilis in the present study increased continuously with increasing food intake, which is unusual in fish feeding on other food sources. However, when prey are very large rel- ative to the predator, as was the case here, a single prey enters the gut at a time and its gut residence time (and thus its digestion) is probably little affected by the next meal, in contrast to the situation with other food sources.

The value of $G C E_{\max }$ (i.e., at $F I_{\max }$ ) increased with increasing body size in $H$. longifilis. Size-dependent increases in $G C E$ are frequent during the larval and early juvenile stages of fishes, because of the development of digestive enzymes (Kamler 1992; Kolkovski 2001). In H. longifilis, this size-dependent increase could also be accounted for by the shift from a purely aquatic respiration to an aerial respiration through the development of suprabranchial organs (transition at about $50 \mathrm{mg} \mathrm{WM}$, as in the sharptooth catfish Clarias gariepinus; Moussa 1956). Aerial respiration is more efficient than aquatic respiration in extracting oxygen from the ambient medium, and this could also be part of the reason why $G C E_{\max }$ in juvenile $H$. longifilis (0.75-0.80) was higher than in most other species documented to date (syntheses in Kamler 1992; Jobling 1994; Baras et al. 2011; Baras 2013).

Cannibalistic larvae and juveniles of $H$. longifilis can grow at very fast rates, as they combine high food intake and high $G C E$, which is not frequent in fishes (Checkley 1984; Houde and Zastrow 1993; Parra and Yúfera 2001), but not exceptional either for cannibals (B. moorei, Baras et al. 2000; P. punctifer, Baras et al. 2011; H. nemurus, Baras et al. 2013). One truly exceptional feature of $H$. longifilis is the extremely shallow slope of the (log-log) $G-D M$ relationship, i.e., -0.16 , whereas values of -0.30 to -0.45 are much more frequent in fishes (synthesis in Jobling 1994). Such a shallow slope, when combined to a high value of the intercept of the same relationship, indicates that the capacity for growth of the species is high at the larval stage and declines very little with increasing fish size. These traits further support the idea that $H$. longifilis is a most valuable candidate for the diversification of aquaculture, wherever fast growth is desirable.

It is worth noting that the $G_{\max }$ model for $H$. longifilis was constructed here from data points originating from 57\% (16 of 28) of the individuals under study, which were originally selected at random. This observation suggests that the fastgrowing capacities documented here are shared by a substantial proportion of a progeny, and not by just a "happy few" that would be predestined to become cannibals because of their exceptionally high capacities for growth. This trend is not unique 
among fish species with strong cannibalistic habits (for further discussion on this topic, see Baras and Lucas 2010; Baras 2013; Baras et al. 2013).

\subsection{Is the use of $G C E_{\max }$ a reliable index of optimal foraging for cannibalistic fishes?}

The optimal foraging theory has been debated for a while, and recent studies or modelling attempts (e.g., Giacomini et al. 2013) further raised the question regarding whether fish maximize energy intake rates or if they minimize foraging expenditures. These questions are certainly of interest for broad prey spectra but have a lower echo in the context of cannibalism in species with high ingestion capacities, as satiation can be attained after eating a single prey and energy expenditures are limited in experimental environments of small dimensions. Likewise, the question of whether optimal foraging is driven by the capacity of growing as fast as possible, or by the optimization of food conversion efficiency is of limited interest in the particular context of cannibalism, because GCE increases with food intake (and thus with growth). This trend was observed here, but also in every study where the bioenergetics of cannibalistic fishes was investigated (e.g., Baras et al. 2010, 2011, 2013)

\subsection{Size-dependent variations of optimal prey size (DM topt $)$}

At any particular body size of cannibals and feeding level, the relationship between $G C E$ and prey size in H. longifilis followed a logarithmic quadratic (dome-shaped) curve (Fig. 4), implying that the growth penalty for consuming prey $n \%$ smaller than $D M_{o p t}$ was more severe than for prey $n \%$ larger than $D M_{\text {opt }}$. Similar asymmetric dome-shaped patterns have been documented in studies on the effect of pellet diameter on fish growth (e.g., Tabachek 1988; Hossain et al. 2000; Azaza et al. 2010). This asymmetric shape can be accounted for by the allometric scaling of food particle volumes, surfaces and diameters, which intimately govern their energy content, digestibility and detectability (or escape capacities for a live prey), respectively.

In $H$. longifilis, the value of $D M_{\text {opt }}$ decreased in cannibals of increasing size, which can be accounted for by at least four complementary factors.

(1) In general, fishes select preferentially - or are more efficient at capturing - prey that represent a certain proportion of their gape, mouth width or section (Shirota 1970; Cunha and Planas 1999). In H. longifilis, there is a slightly negative allometric growth of mouth dimensions and a positive allometric growth of body depth (Baras 1999). Furthermore, the elasticity of mouthparts generally decreases in larger fish (Baras 2013). Altogether these traits restrict progressively the size of the largest conspecific that can be eaten and they also probably impact the value of $D M_{o p t}$.

(2) The skeleton and finrays of small prey are little ossified, and proportionally more flexible than those of larger conspecifics, and these differences are also likely to complicate the handling and ingestion of large prey by cannibals of increasing size. Conversely, the greater flexibility of the body of small prey together with the greater elasticity of the mouthparts of small cannibals is likely to challenge the relevance of predictions of maximal prey size that are calculated on the basis of morphological measurements. This was the case here, as small cannibals (categories 1 and 2) were found to eat some prey that were beyond their supposed maximal ingestion capacities (Fig. $1 \mathrm{vs}$. information presented in Baras 1999 and 2013).

(3) If the cost for prey capture is very low, which is likely in environments of small dimensions, then the value of $D M_{o p t}$ is essentially governed by the digestibility of the prey. Digestibility depends on the surface:volume ratio of the prey and is thus inversely proportional to its size, thereby causing $D M_{o p t}$ to shift downwards in cannibals of increasing size.

(4) Prey capture is less energy-demanding in small-size environments with high prey density than in large environments with low prey density (Juanes 1994; Giacomini et al. 2013). This also applies to situations where fish grow in an environment of unchanged dimensions, as was precisely the case here, because the relative prey density increases and the relative size of the environment decreases as the cannibals grow bigger. In this context, the energy penalty for capturing many small prey is reduced and probably traded off by their easier capture, greater digestibility and lower risk of retaliation.

\subsection{Are prey size preferences contextual?}

Here, cannibalistic larvae and juveniles of $H$. longifilis exhibited marked prey size-preferences at all ages or sizes, but their preferred prey sizes were about 2.5-3.0 times smaller than in a previous study on cannibalism in this species under controlled conditions (Baras 1999). In the latter study, the environment size was deeper and larger $(50 \mathrm{~L} v s .2 \mathrm{~L})$, prey density was lower (1-5 fish $\mathrm{L}^{-1}$ vs. about 10 fish $\mathrm{L}^{-1}$ ) and there were several (nine) potential cannibals in every tank. As discussed above, environmental conditions that make prey capture more energy-demanding (large environment size relative to fish size) or uncertain (competition) are likely to promote the selection of large prey. Likewise, the use of the water column by fish is frequently size-structured in deep environments (i.e., relative to fish size; for H. longifilis, see Baras 1999), thereby increasing the probability that cannibals encounter large rather than small prey. Finally, it is more difficult for a prey being chased by a large cannibal to escape the attack of another cannibal, even if the two predators do not cooperate in the strict sense. All these factors concurred to favouring the selection of large prey in the rearing conditions in the study by Baras (1999) and of small prey in the present study. This interpretation also partly accounts for why cannibals of increasing size in the present study ate preferentially prey of decreasing size relative to their own, as they grew in environments of unchanged dimensions.

This difference between the two studies highlights that prey size preference in cannibalistic fish can vary substantially, even between two sizes of environments that could both be viewed as strongly restricted at first sight (i.e., a 50-L aquarium is not particularly large for rearing fish of 1 to $10 \mathrm{~g} \mathrm{WM}$ ). 
This example adds to the well-known difficulty of up-scaling results from experimental situations to rearing environments in fish farms. However, the comparison between the results presented here and in Baras (1999) is useful in that it probably provides the upper and lower limits of prey size preferences for cannibalistic $H$. longifilis under culture conditions. Indeed fish could hardly be reared in environments smaller than here, so it is unlikely that they would prefer smaller prey, and cannibals in 50-L aquaria preferred prey that were close to their maximal ingestion capacities (Baras 1999). Based on these assumptions, the preferred prey sizes of $H$. longifilis would range from 10 to $20 \% D M$ and from 5 to $15 \% D M$, in cannibals of 6 and $300 \mathrm{mg} D M$, respectively (corresponding ranges of 53-71 and $41-57 \% S L$, respectively). In view of the marked propensity of cannibalistic $H$. longifilis to consume very large prey in environments as small as $50 \mathrm{~L}$, recommendations for sizegrading in aquaculture facilities should be based on the most pessimistic (highest) estimates.

\subsection{Prey size preference and optimal foraging in cannibalistic $\boldsymbol{H}$. longiflis: a matter of body size or experience?}

The role of experience in fishes exercising piscivory has been demonstrated in terms of increased tendency to attack (Godin 1978; Milinski 1979) or higher capture efficiency (Gillen et al. 1981; Croy and Hughes 1991; Wahl et al. 1995). In the context of cannibalism, there have been several reports of situations following size-grading in aquaculture facilities where inexperienced cannibals suffocated while attempting to ingest prey that were excessively large relative to their ingestion capacities (Brabrand 1995; Hseu et al. 2007), whereas such situations were never observed prior to size-grading. These observations suggest that individual experience in cannibalism can impact on prey size selectivity as well.

During the present study, naive cannibals of $H$. longifilis consumed preferentially prey that were larger than optimal, but their preferences shifted progressively to prey sizes close to optimal $_{t}$ with increasing time in the predation cages, and thus possibly with experience (series A and B, Table 4). Yet, this is no unequivocal demonstration that cannibals of $H$. longifilis foraged in a more optimal way with increasing experience, as in each experimental series, experience was strongly correlated with cannibal's size. Furthermore, there was striking evidence that the ratio between the preferred and optimal prey sizes of experienced cannibals at the end of a particular experimental series was most similar to those of naive cannibals of a similar size at the start of the next experimental series. This observation suggests that prey size preference and the capacity of foraging optimally in cannibalistic $H$. longifilis in the present study were rather a matter of body size (absolute body size or relative to the experimental environment) than a matter of experience.

The view that individual experience was of secondary importance as regards prey size selectivity in cannibalistic $H$. longifilis, was supported by the finding that in every experimental series (A-D) of the present study the food intake of cannibals (relative to $F I_{\max }$ ) did not vary significantly with fish experience. It is not claimed that experience had no influence at all on cannibalistic behaviour, for example on the propensity to attack, capture success per strike or prey handling time, but these variables were not measured here.

\section{Conclusion}

The present study is one of the very rare evidences that the optimal foraging theory applies to cannibalism/piscivory in fishes, at least in environments where escape capacities are limited, prey are abundant and in absence of competition. In contrast to many other studies in fishes, it is strongly suggested here that individual experience is of secondary importance in shaping prey size preference and capacity of cannibalistic fish to forage optimally. Yet, as stated above, the prey size preferences of cannibals are probably labile and can shift substantially between different environment sizes or contexts (possible competition between predators). To this respect, it is worth asking again a question that was raised about 15 years ago as regards the time scale that makes prey size preference truly optimal (Baras 1999), i.e., is optimal foraging a matter of tactics (short term) or strategy (long term)?

Cannibals that select small, more digestible prey can display a higher $G C E$ and growth, but they incur the risk that larger prey eventually grow beyond their reach. By contrast, when selecting the largest prey at hand, GCE is not maximised, but the stock of available prey - which can be exploited over a longer period and more thoroughly - is higher, thereby giving a long-term benefit to cannibals selecting this strategy (for a comprehensive discussion of this topic, see Baras 1999). In an aquacultural context, the answer to the former question largely depends on the adequacy of feeding schedules and thus to what extent smaller conspecific prey fish feeding on alternative food sources can fulfil their capacities for growth, which are genuinely higher than those of cannibals of larger size. This is just another encouragement to feed young fish adequately to minimize cannibalism.

Acknowledgements. The authors wish to thank Christophe Cochet for technical assistance and two anonymous referees for constructive comments on the original draft of the manuscript. Mrs. Dominique Baras-Caseau contributed to improve the English style of the manuscript. Etienne Baras is an honorary research associate of the Belgian FNRS.

\section{References}

Amundsen P.-A., Damsgard B., Arnesen A.M., Jobling M., Jorgensen E.H., 1995, Experimental evidence of cannibalism and prey specialization in Arctic charr, Salvelinus alpinus. Environ. Biol. Fishes 43, 285-293.

AOAC International, 1995, Official Methods of Analysis of AOAC International. Arlington VA, AOAC International.

Atse B.C., Konan K.J., Alla Y.L., Pangini K., 2009, Effect of rearing density and feeding regimes on growth and survival of African catfish Heterobranchus longifilis (Valenciennes, 1840) larvae in a closed recirculating aquaculture system. J. Appl. Aquac. 21, 193-195.

Azaza M.S., Dhraief M.N., Kraiem M.M., Baras E., 2010, Influences of food particle size on growth, size heterogeneity, food intake and gastric evacuation in juvenile Nile tilapia, Oreochromis niloticus L., 1758. Aquaculture 309, 193-202. 
Baras E., 1999, Sibling cannibalism among juvenile vundu under controlled conditions: I. Cannibalistic behaviour, prey selection and prey size selectivity. J. Fish Biol. 54, 82-105.

Baras E., 2013, Cannibalism in fish larvae: what have we learned? In: Qin J.G. (Ed.), Larval Fish Aquaculture. New York: Nova Publishers, pp. 167-199.

Baras E., Hafsaridewi R., Slembrouck J., Priyadi A., Moreau Y., Pouyaud L., Legendre M., 2010, Why is cannibalism so rare among cultured larvae and juveniles of Pangasius djambal ? Morphological, behavioural and energetic answers. Aquaculture $305,42-51$.

Baras E., Hafsaridewi R., Slembrouck J., Priyadi A., Moreau Y., Pouyaud L., 2013, Do cannibalistic fish possess an intrinsic higher growth capacity than others? A case study in the Asian redtail catfish Hemibagrus nemurus (Valenciennes, 1840). Aquac. Res. 45, 68-79.

Baras E., Jobling M., 2002, Dynamics of intracohort cannibalism in cultured fish. Aquac. Res. 33, 461-479.

Baras E., Lucas M.C., 2010, Individual growth trajectories of sibling Brycon moorei raised in isolation, and their relationship with aggressive behavior. J. Fish Biol. 77, 985-997.

Baras E., Ndao M., Maxi M.Y.J., Jeandrain D., Thomé J.P., Vandewalle P., Mélard C., 2000, Sibling cannibalism in dorada under experimental conditions. I. Ontogeny, dynamics, bioenergetics of cannibalism and prey selectivity. J. Fish Biol. 57, 10011020.

Baras E., Silva del Aguila D.V., Montalvan Naranjos G.V., Dugué R., Chu Koo F., Duponchelle F., Renno J.F., Garcia- Dávila C., Nuñez J., 2011, How many meals a day to minimize cannibalism when rearing larvae of the Amazonian catfish Pseudoplatystoma punctifer? The cannibal's point of view. Aquat. Living Resour. 24, 379-390.

Baras E., Tissier F., Philippart J.-C., Mélard C., 1999, Sibling cannibalism among juvenile vundu under controlled conditions. II. Effect of body weight and environmental variables on periodicity and the intensity of type II cannibalism. J. Fish Biol. 54, 106-118.

Brabrand A., 1995, Intracohort cannibalism among larval stages of perch (Perca fluviatilis). Ecol. Freshw. Fish 4, 70-76.

Canale R.P., Breck J.E., 2013, Comments on proper (and improper) solutions of bioenergetic equations for modelling fish growth. Aquaculture 404-405, 41-46.

Checkley D.M. Jr., 1984, Relation of growth to ingestion for larvae of Atlantic herring Clupea harengus and other fish. Mar. Ecol. Prog. Ser. 18, 215-224.

Croy M.I., Hughes R.N., 1991, The role of learning and memory in the feeding behaviour of the fifteen-spined stickleback (Spinachia spinachia L.). Anim. Behav. 41, 161-170.

Cunha I., Planas M., 1999. Optimal prey size for early turbot larvae (Scophthalmus maximus L.) based on mouth and ingested prey size. Aquaculture 176, 103-110.

Dos Santos J., Burkow I.C., Jobling M., 1993, Patterns of growth and lipid deposition in cod (Gadus morhua L.) fed natural prey and fish based feeds. Aquaculture 110, 173-189.

Emlen J.M. 1966, The role of time and energy in food preferences. Am. Nat. 100, 611-617.

Folkvord A., 1997, Ontogeny of cannibalism in larval and juvenile fishes with special emphasis on Atlantic cod. In: Chambers R.C., Trippel E.A. (Eds.), Early Life History and Recruitment in Fish Populations. London: Chapman and Hall, pp. 251-278.

Folkvord A., Otterå H., 1993, Effects of initial size distribution, day length, and feeding frequency on growth, survival and cannibalism in juvenile Atlantic cod (Gadus morhua L.). Aquaculture $114,243-260$.
Giacomini H.C., Shuter B.J., Lester N.P., 2013, Predator bioenergetics and the prey size spectrum: Do foraging costs determine fish production? J. Theor. Biol. 332, 249-260.

Gillen A.L., Stein R.A., Carline R.F., 1981, Predation by pellet-reared tiger muskellunge on minnows and bluegills in experimental systems. Trans. Am. Fish. Soc. 110, 197-209.

Gilles S., Dugué R., Slembrouck J., 2001, Manuel de production d'alevins du silure africain Heterobranchus longifilis. Paris, Maisonneuve and Larose.

Godin J.-G.J., 1978, Behavior of juvenile pink salmon (Oncorhynchus gorbuscha Walbaum) toward novel prey: influence of ontogeny and experience. Environ. Biol. Fishes 3, 261-266.

Goldan O., Popper D., Karplus I., 1997, Management of size variation in juvenile gilthead seabream (Sparus aurata) I: particle size and frequency of feeding dry and live food. Aquaculture 152, 181190.

Hart P.J.B., Hamrin S.F., 1990, The role of behaviour and morphology in the selection of prey by pike. In: Hughes R.N. (Ed.), Behavioural Mechanisms of Food Selection. Berlin: SpringerVerlag, pp. 219-233.

Hasan M.R., Macintosh, D.J., 2008, Optimum food particle size in relation to body size of common carp, Cyprinus carpio L., fry. Aquac. Res. 23, 315-325.

Hecht T., Appelbaum S., 1988, Observations on intraspecific aggression and coeval sibling cannibalism by larval and juvenile Clarias gariepinus (Clariidae: Pisces) under controlled conditions. J. Zool. (London) 214, 21-44

Hecht T., Oellermann L., Verheust L., 1996, Perspectives on clariid culture in Africa. Aquat. Living Resour. 9, Spec. Issue, 197-206.

Hecht T., Pienaar A.G., 1993, A review of cannibalism and its implications in fish larviculture. J. World Aquac. Soc. 24, 246-261.

Hossain M.A.R., Haylor G.S., Beveridge M.C.M., 2000, The influence of food particle size on gastric emptying and growth rates of fingerling African catfish, Clarias gariepinus Burchell, 1822. Aquac. Nutr. 6, 73-76.

Houde E.D., Zastrow C.E., 1993, Ecosystem- and taxon-specific dynamic and energetics properties of larval fish assemblages. Bull. Mar. Sci. 53, 290-335.

Hoyle J.A., Keast A., 1987, The effect of prey morphology and size on handling time in a piscivore, the largemouth bass (Micropterus salmoides). Can. J. Zool. 65, 1972-1977.

Hseu J.-R., Chang H.-F., Ting Y.-Y., 2003, Morphometric prediction of cannibalism in larviculture of orange-spotted grouper, Epinephelus coioides. Aquaculture 218, 203-207.

Hseu J.-R., Huang W.-B., 2014, Application of logistic regression analysis to predict cannibalism in orange-spotted grouper, Epinephelus coioides (Hamilton) fry. Aquac. Res. 45, 868-873.

Hseu J.-R., Huang W.-B., Chu Y.-T., 2007, What causes cannibalization-associated suffocation in cultured brownmarbled grouper, Epinephelus fuscoguttatus (Forsskål, 1775)? Aquac. Res. 38, 1056-1060.

Hseu J.-R., Hwang P.P., Ting Y.Y., 2004, Morphometric model and laboratory analysis on intracohort cannibalism in giant grouper Epinephelus lanceolatus fry. Fish. Sci. 70, 482-486.

Jobling M., 1987, Influences of food particle size and dietary energy content on patterns of gastric evacuation in fish: test of a physiological model of gastric emptying. J. Fish Biol. 30, 299-314.

Jobling M., 1994, Fish Bioenergetics, London: Chapman and Hall.

Jobling M., Wandsvik A., 1983, An investigation of factors controlling food intake in Arctic charr, Salvelinus alpinus L. J. Fish Biol. 23, 391-404. 
Johnson J.M., Post D.M., 1996, Morphological constraints on intracohort cannibalism in age- 0 largemouth bass. Trans. Am. Fish. Soc. $125,809-812$.

Juanes F., 1994, What determines prey size selectivity in piscivorous fishes? In: Stouder D.J., Fresh K.L., Feller R.J. (Eds.), Theory and Application in Fish Feeding Ecology. Columbia: South Carolina University Press, Belle W. Baruch Library in Marine Sciences No. 18 , pp. $79-100$.

Juanes F., 2003, The allometry of cannibalism in piscivorous fishes. Can. J. Fish. Aquat. Sci. 60, 594-602.

Juanes F., Buckel J.A., Scharf F.S., 2002, Feeding ecology of piscivorous fishes. In: Hart P.J.B., Reynolds J.D. (Eds.), The Handbook of Fish Biology and Fisheries. Vol. 1: Fish Biology. London: Blackwell Scientific Publications, pp. 267-283.

Kamler E., 1992, Early Life History of Fish. London: Chapman and Hall.

Kerdchuen N., Legendre M., 1994, Larval rearing of an African catfish, Heterobranchus longifilis (Teleostei, Clariidae): a comparison between natural and artificial diets. Aquat. Living Resour. 7, 247-253.

Knights B., 1983, Food particle-size preferences and feeding behaviour in warmwater aquaculture of European eel, Anguilla anguilla (L.). Aquaculture 30, 173-190.

Kolkovski S., 2001, Digestive enzymes in fish larvae and juveniles - implications and applications to formulated diets. Aquaculture 200, 181-201.

Krebs J.R., Stephens D.W., 1986, Foraging theory. Princeton, NJ: Princeton University Press.

Legendre M., 1986, Seasonal changes in sexual maturity and fecundity, and HCG-induced breeding of the catfish, Heterobranchus longifilis Val. (Clariidae), reared in Ebrie Lagoon (Ivory Coast). Aquaculture 55, 201-213.

Legendre M., Teugels G.G., Cauty C., Jalabert B., 1992, A comparative study of the growth rate and reproduction of Clarias gariepinus (Burchell, 1822), Heterobranchus longifilis Valenciennes, 1840, and their reciprocal hybrids (Pisces, Clariidae). J. Fish Biol. 40, 59-79.

MacLean A., Huntingford F.A., Armstrong J.D., Ruxton G.D., 2003, Fish don't read textbooks: juvenile salmon prove ignorant of foraging theory. J. Fish Biol. 63 (suppl. A), 236-237.

Milinski M., 1979, Can an experienced predator overcome the confusion of swarming prey more easily? Anim. Behav. 27, 11221126.

Mittelbach G.G., 1981, Foraging efficiency and body size: a study of optimal diet and habitat use by bluegills. Ecology 62, 1370-1386.

Mittelbach G.G., Persson L., 1998, The ontogeny of piscivory and its ecological consequences. Can. J. Fish. Aquat. Sci. 55, 1454 1465.
Moussa T.A., 1956, Morphology of the accessory air-breathing organs of the teleost, Clarias lazera (C. and V.). J. Morphol. 98, 125-160.

Nwosu F.M., Holzlöhner S., 2000, Influence of temperature on egg hatching, growth and survival of larvae of Heterobranchus longifilis Val. 1840 (Teleostei: Clariidae). J. Appl. Ichthyol. 16, 20-23.

Otémé Z., Hem J.S., Legendre M., 1996, Nouvelles espèces de poissons-chats pour le développement de la pisciculture africaine. Aquat. Living Resour. 9, Spec. Issue, 207-217.

Parra G., Yúfera M., 2001, Comparative energetics during early development of two marine fish species, Solea senegalensis (Kaup) and Sparus aurata (L.). J. Exp. Biol. 204, 2175-2183.

Persson L., 1986, Patterns of food evacuation in fishes: a critical review. Environ. Biol. Fishes 16, 51-58.

Pyke G.H., Pulliam H.R. Charnov E.L., 1977, Optimal foraging: a selective review of theory and tests. Q. Rev. Biol. 52, 137-154.

Qin J., Fast A.W., 1996, Size and feed dependent cannibalism with juvenile snakehead Channa striatus. Aquaculture 144, 313-320.

Scharf F.S., Juanes F., Sutherland M., 1998, Inferring ecological relationships from the edges of scatter diagrams: a comparison of least squares and quantile regression techniques. Ecology 79, 448-460.

Shirota A., 1970, Studies on the mouth size of fish larvae. Bull. Jpn. Soc. Sci. Fish. 36, 353-368 (In Japanese with English summary).

Sih A., Christensen B., 2001, Optimal diet theory: when does it work, and when and why does it fail? Anim. Behav. 61, 379-390.

Sogard S.M., Olla B.L., 1994, The potential for intracohort cannibalism in age-0 walleye pollock, Theragra chalcogramma, as determined under laboratory conditions. Environ. Biol. Fishes 39 , 183-190.

Tabachek J.L., 1988, The effect of feed particle size on growth and feed efficiency of Arctic charr (Salvelinus alpinus (L.)). Aquaculture 71, 319-330.

Wahl D.H., Einfalt L.M., Hooe M.L., 1995, Effect of experience with piscivory on foraging behavior and growth of walleyes. Trans. Am. Fish. Soc. 124, 756-763.

Wahl D.H., Stein R.A., 1988, Selective predation by three esocids: the role of prey behavior and morphology. Trans. Am. Fish. Soc. $117,142-151$.

Wankowski J.W.J., Thorpe J.E., 1979, The role of food particle size in the growth of juvenile Atlantic salmon (Salmo salar L.). J. Fish Biol. 14, 351-370.

Werner E.E., Gilliam J.F., 1984, The ontogenetic niche and species interactions in size-structured populations. Annu. Rev. Ecol. Syst. $15,393-425$.

Werner E.E., Hall D.J., 1974, Optimal foraging and the size selection of prey by the bluegill sunfish (Lepomis macrochirus). Ecology $55,1042-1052$. 